\title{
Causes and Consequences of Divorce - The Context of Kosovo
}

\author{
Egzonis Hajdari ${ }^{1}$ ¿ \\ Fulya Erlüle² (iD) \\ "Lecturer at College "ILIRIA", Pristina, Kosovo \\ Email: egzonishajdari@gmail.com \\ Professor at Marmara University, Istambul, Turkey \\ Email:fulius@hotmail.com
}

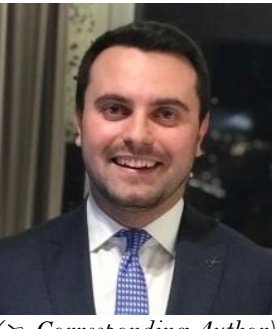

\section{Abstract}

Divorce is an ancient institution of marital law that was born shortly after marriage. This institution is known by ancient laws, as well as by contemporary laws. In Kosovo the issue of divorce is regulated by Family Law. This law addresses besides principle divorce issues (divorce modalities, initiative and decision-making subjects, proceedings etc.), as well as the causes of divorces. Such issues, in an identical manner are regulated also by Turkish Civil Code. Modest results of this scientific paper indicate the fact that the issue of divorce in Kosovo constitutes a complicated and a relatively wide extent phenomenon. Consequently, in Kosovo society of these past five years $(2010-2014)$ were recorded 6388 divorce cases. Divorce cases have manifested a different presence degree observing this in the context of causes determining this harmful phenomenon. Divorce whenever and wherever happens it causes numerous social and psychological consequences etc. which significantly hit spouses, their children but also society in general. During the preparation of this scientific paper we used historical-legal, legal, comparative, statistical and sampling methods.

Keywords: Marriage, Divorce, Fidelity, Unbearable life, Intention.

Citation | Egzonis Hajdari; Fulya Erlüle (2018). Causes and Consequences of Divorce - The Context of Kosovo. Asian Journal of Social Sciences and Management Studies, 3(1): 32-39. History:

Received: 24 January 2018

Revised: 16 February 2018

Accepted: 20 February 2018

Published 28 Februay 2018

Licensed: This work is licensed under a Creative Commons

Attribution 3.0 License $(\mathrm{cc})$

Publisher:Asian Online Journal Publishing Group
Contribution/Acknowledgement: All authors contributed to the conception and design of the study.

Funding: This study received no specific financial support.

Competing Interests: The authors declare that they have no conflict of interests.

Transparency: The authors confirm that the manuscript is an honest, accurate, and transparent account of the study was reported; that no vital features of the study have been omitted, and that any discrepancies from the features of the study have been omit
study as planned have been explained.

study as planned have been explained.
Ethical: This study follows all ethical practices during writing.

\section{Contents}

1. Introduction

2. The Meaning of Divorce

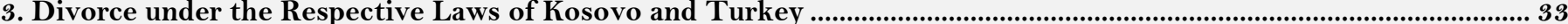

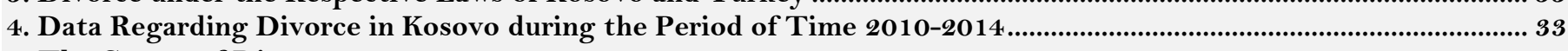

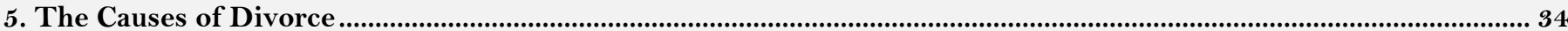

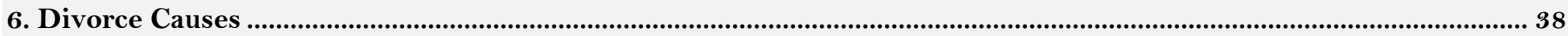

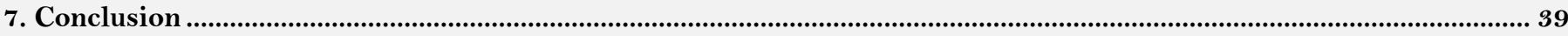

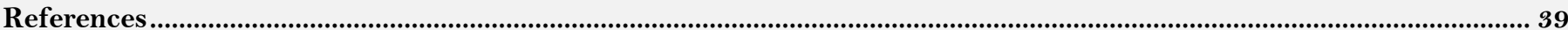

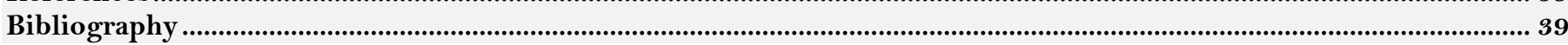




\section{Introduction}

Divorce as a marital law institution occupies an important place in the relevant laws and in the theory of family law. Divorce has a long history that has been treated in old laws as well as in modern ones. Divorce is a complicated phenomenon. It was such in the past, but also nowadays. It is determined by numerous causes and expresses a lot of consequences of different natures. This Research of divorce is focused in Kosovo. The result of this scientific paper prove that in the appearance of divorce in Kosovo society during the research period (2010 2014) have influenced numerous circumstances, such making spouses life unbearable including adultery, assassination against the life of the spouse, serious maltreatment, ill-intended and unjustifiable abandonment, incurable mental illness and continuous incapacity to act, unreasonable interruption of factual cohabitation for more than one year and divorce by mutual agreements. Regarding these issues were presented, analyzed and commented important statistical data. In the following of this scientific paper has been treated the consequences of divorce.In this regard were elaborated in terms of existing data, social, psychological and other consequences which hit divorced spouses, their family and children and society in general. In addition, in this scientific paper, although briefly were treated also determining factors of divorce in Kosovo society. In this regard has been emphasized the role of social and family democratic transition that included Kosovo society, the advancement of educational, cultural and social women position, deep multi-dimensional transformation that included Kosovo family by hitting patriarchal family, economic, residential problems etc.

\section{The Meaning of Divorce}

Marriage is one of the oldest institutions, and certainly the most important social-law institution (Janić et al., 1990). It is defined as a free union of life of a man and a woman bond in front of the competent body by expressing freely the consent according to the procedure foreseen by legal provisions, a solemn act based on moral and legal equality, in the sense of love, respect and mutual understanding (Podvorica, 2011). On the other hand, divorce is an ancient institution of marital law estimated to have been born shortly after the birth marriage. Divorce throughout the human history until nowadays it is considered to be the most faithful ally of marriage. It was recognized and regulated by Roman, Greek, Byzantine Law etc. (Janić et al., 1990). as well as Turkish Early Law and Albanian Customary Law (Elezi, 1983). These laws mainly recognized two forms of marriage dissolution: the one resulting by spouse's agreement and dissolution of marriage by the request of one spouse. In fact divorce as a marital law institution is known without limitations by all contemporary laws.

Consequently, by divorce is understood the dissolution of a valid marriage based on grounds determined by the law and according to the legal proceedings finalized with the issuance of decision by a competent body-court (Podvorica, 2011). This definition it makes clear the fact that by divorce is only dissolved the valid marriage. This means that invalid marriage is not dissolved but it is annulled (Luarasi, 2001).

\section{Divorce under the Respective Laws of Kosovo and Turkey}

In contemporary societies issues related to marriage, including divorce are regulated by respective laws. Regarding Kosovo this issue is regulated by Family Law. ${ }^{1}$ This law addresses divorce in articles 68 and 69 . In the article 68 paragraphs 1-4 are regulated some of the divorce principal issues and divorce modalities, initiative and decision-making subjects, as well as divorce proceedings (Gashi et al., 2012). According to solutions foreseen in this article marriage may be dissolved by divorce only upon decision of a court or if one spouse or both by mutual agreement may request a divorce by filing a claim with the competent court. The right to file a claim cannot be passed on to successors but the successors of the plaintiff may continue the commenced procedure, to verify the foundation of the complaint. The decision-making concerning divorce is an exclusively right of the court, which concerning this issue conducts main hearing in which are invited and can be declared about it both spouses. In meanwhile, the article 69, paragraph 1 regulates the issue of divorce causes. According to the solutions foreseen in this provision the spouse may request divorce when marital relations have seriously and continuously become disordered or when due to other reasons the marriage has irretrievably broken down. Whereas the paragraph 2 of this article addresses the special reasons of divorce. Such reasons pursuant to this legal provision may be considered: unbearable life of spouses, adultery, assassination against the life of the spouse, serious maltreatment, ill-intended and unjustifiable abandonment, incurable mental illness and continuous incapacity to act, unreasonable interruption of factual cohabitation for more than one year and divorce by mutual agreement.

Turkish Civil Code the issue of divorce causes has regulated by articles 161-166. By articles 161-165 this Code addresses specific causes of divorce. As such causes legal solutions included in these articles consider: adultery, bad and degrading behavior (offensive etc), crimes and unfair behaviors, ill-intended and unjustifiable abandonment and mental illness (Helvacı and Erlüle, 2014) Whereas general causes of divorce The Civil Code of the Republic of Turkey addresses in the article 166. As such causes this Code considers: instability in the unity of marriage (paragraphs 1 and 2), divorce by contract (paragraph 3) and divorce due to the repeated failure in order to create a joint life (paragraph 4). Certainly this Code, similar as Kosovo Marital Law through its solutions regulates also the principled issues of divorce, including those addressed by initiative and decision-making divorce subjects (Sahatqija, 1987).

\section{Data Regarding Divorce in Kosovo during the Period of Time 2010-2014}

In Kosovo the issue of divorce in the last fifteen years is quite current. The actuality of this issue has been determined by the fact that divorces during the post-war period (1999) are more frequent in comparison to the past. Thus, in 2010 were divorced 1488 couples of spouses, whereas in 2014 were divorced 1249 other couples of spouses. In a special diagram, due to the lack of data for previous years, will be presented the data for the number and performance of divorces in Kosovo during the period of time 2010-2014. 
In total: 6388
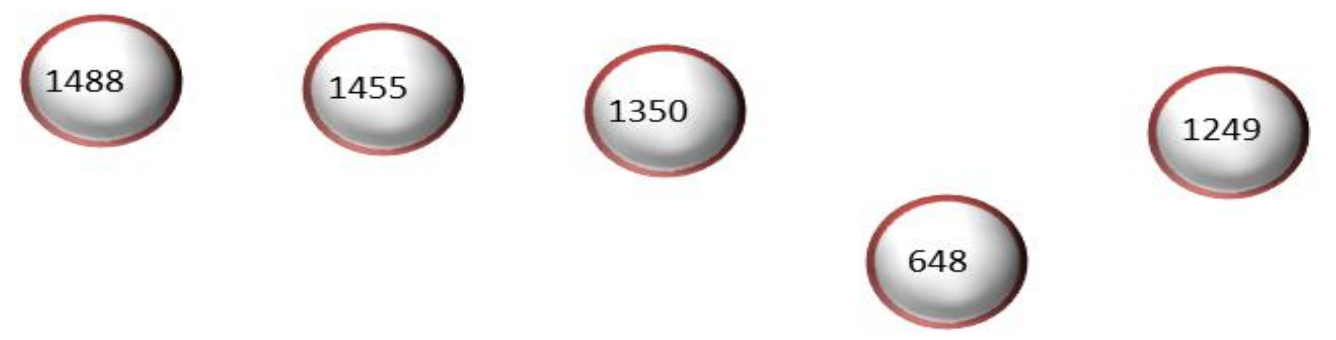

2009

2010

2011

2012

2013

2014

2015

Diagram No-1. The number and performance of divorces

According to these data during the period of time 2010-2014 in Kosovo were divorced 6388 couples of spouses. ${ }^{2}$ Data reflected in this table indicate that during the five years research period the number of divorces is relatively high. This situation is considered to be as a result of democratization reports processes that included Kosovo society generally, the advancement of educational, cultural and economic women position, family transition (from patriarchal families to contemporary) but also the existence of many accumulated problems from the past determined by customary rules handed down from generation to generation.

\section{The Causes of Divorce}

The causes of divorce are facts and circumstances arising after the marriage. They constitute grounds for which may be requested the dissolution of marriage. The causes of divorce are numerous and diverse. As such they are general and special (Traljić and Babić, 2004).

\subsection{The General Causes}

As general causes of divorce are considered serious and constant disorders of marital relations, to such a high level as the realization of the purpose of marriage and further continuation of joint living spouses make it impossible. Serious disorder element it cannot be separated from the element that continuation of marriage it makes impossible (Sahatqija, 1987). These two elements are closely linked to each other, because marriage is considered to be shocked exactly when its continuation is impossible. Marital relations are disordered usually due to the violation of marital obligations by one or both spouses. These violations of obligations are required to be severe and constant such that wedlock life becomes unbearable. The continuity of violating the obligations ${ }^{3}$ indicates non-perspective of community and deepening of disorder (Janić et al., 1990). Due to the large number of general causes which may include different facts and circumstances, it is impossible to count them as specified by law. But as such may be considered: severe economic situation, religious and cultural tensions, frustration in marriage, profound family transition, the advancement of women educational position etc.

\subsection{Special Causes}

Special causes of divorce are numerous and of different nature. They are facts and circumstances specified explicitly by legal norms. As it is specified above, the article 69 of Family Law of Kosovo has determined these divorce causes: unbearable life of spouses, adultery, assassination against the life of the spouse, serious maltreatment, ill-intended and unjustifiable abandonment, incurable mental illness and continuous incapacity to act, unreasonable interruption of factual cohabitation for more than one year and divorce by mutual agreement. In the following of this scientific paper will be discussed about each of these causes separately. In this case, unable to study all the court cases of divorce the analysis will focus in analyzing of 90 studied court decisions related to divorce.

\subsubsection{Unbearable Life of Spouses}

Unbearable life of spouses may happen due to the different circumstances which create disorders in well-being of a harmonious life of spouses (Gashi et al., 2012). They are of different natures such as: constant fights, the variance of characters, alcoholism, drug addiction etc. In some cases such circumstances may be not important, but their effect can be such that life of spouses disorder seriously. Thus, in a court case the cause of divorce was husband's negligence (the defendant) to complete visa documents. ${ }^{4}$ This circumstance motivated frequent verbal conflicts between spouses, such that life of spouses led to constant conflicts.

How is manifested the influence of this cause in Kosovo divorce appearance during the period of time 20102014, observed this in the context of studied judgments it may see from data presented in the following diagram.

\footnotetext{
${ }^{2}$ General Statistics During the Years 2010-2014 (2014).

${ }^{s}$ The continuity of violating the obligations comes due to the repetition of marital relations disorder during a long period of time. ${ }^{4}$ District Court (2008).
} 
Constant fights

1122

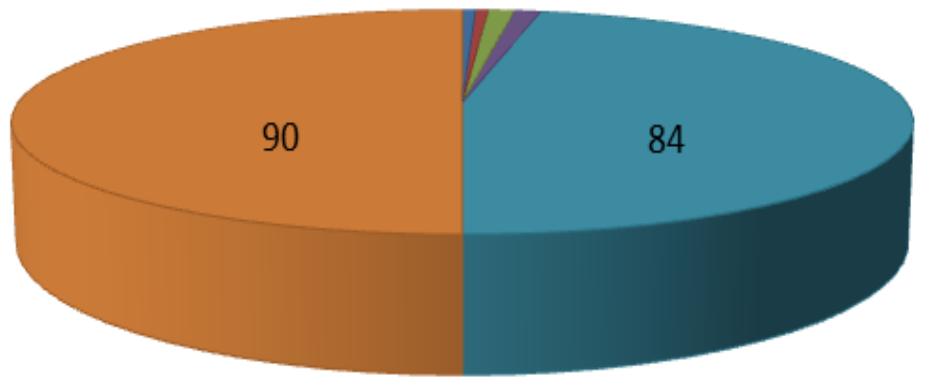

The variance of characters

Alcoholism and drug addiction

Other circumstances of this nature

Other special causes of divorces

\section{$\square$ In total court cases studied}

Diagram No- 2. Number of divorces due to the circumstances that made spouses life unbearable

According to these data from 90 court cases studied in six cases cause of divorces were circumstances that make spouses life unbearable. As it turns out, this cause participates in general number of divorce court studied cases to $6.66 \%$. Among these circumstances in two cases to the divorce had come because of alcoholism and drug addiction, in a case due to the constant fights, in another case due to the variance of characters and in two cases because of other circumstances of this nature. Within these two causes one of the divorces had resulted due to the lack of children, whereas another case due to the continuing refusal of the spouse to engage in kitchen chores. These data indicate that in current conditions when Kosovo society has been included by a profound democratic process, which includes the promotion of socio-economic women position, new circumstances, unknown from the past, are becoming the cause of not few divorces in Kosovo.

\subsubsection{Adultery}

Matrimonial faithfulness is estimated to be an influential factor in preservation and functioning of the marriage. In this regard, by Family Law of Kosovo (article 42, paragraph 3) spouse marital fidelity is defined as a legal obligation (Gashi et al., 2012). Therefore, the violation of marital fidelity constitutes a crucial influential factor in the trend of divorces characterizing Kosovo modern society. The violation of marital fidelity exists when one or both spouses enter into intimate relationships with other persons.

How is manifested the influence of this cause in the appearance of divorces in Kosovo during the period of time 2010-2014, observed this in the context of studied judgments it may be seen from the data presented in the following diagram.

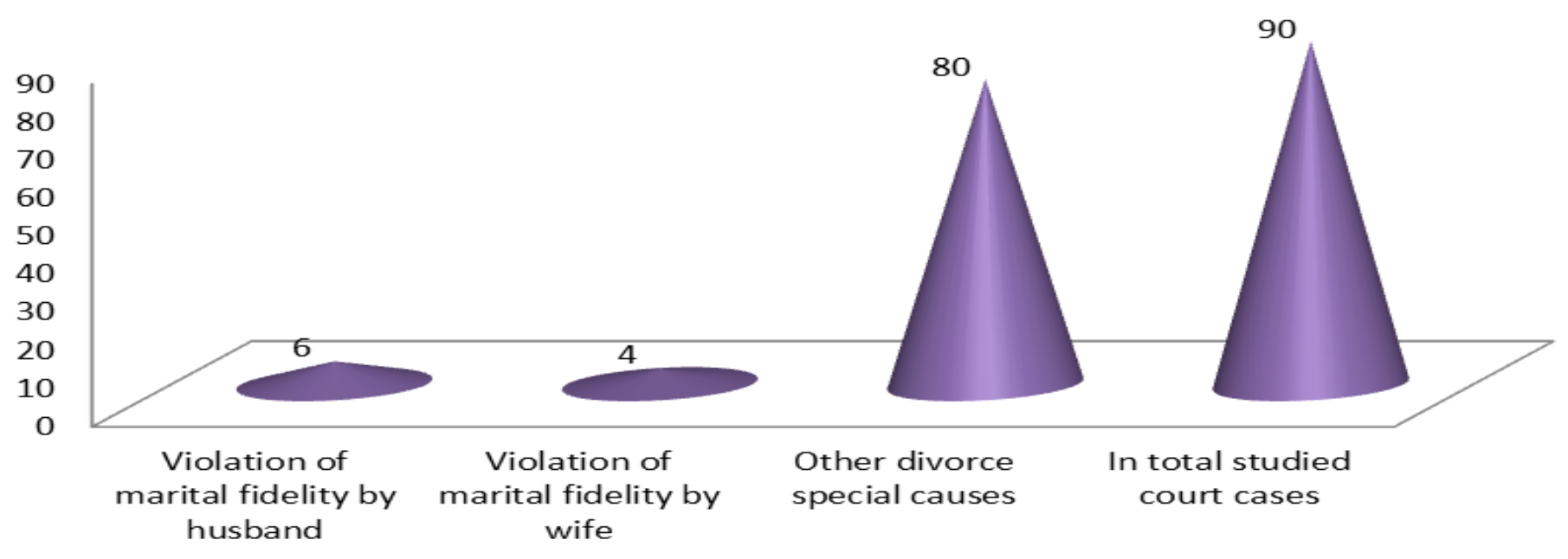

Diagram No-3. The number of divorces due to the violation of marital fidelity

According to these data from 90 studied court cases in 10 cases the cause of divorce was adultery. As it turns out, this cause participates in the general number of divorce studied court cases to $11.11 \%$. From studied court cases results that in six cases had come to the divorce due to the adultery of the husband, whereas in other four cases due to the adultery of wife. The cause of husband higher participation in adultery cases must be linked with the role and bigger commitments that continue to have men in daily life activities. This circumstance puts them more than women to face different challenges, some of these challenges made them to be more provoked in order to violate spouse faithfulness.

\subsubsection{Assassination against the Life of the Spouse}

The commission of criminal offences against the life of the spouse constitutes a ground that also may lead to the divorce. Thus, when one of the spouses commits criminal offence against the life of the other spouse, the spouse against whom the criminal offence has been committed has the right to request divorce (Gashi et al., 2012). In fact regarding this cause of divorce, it is about criminal offences committed against the life of the spouse for example: serious injury, attempted murder etc. In these cases the decision concerning divorce depends on the determination of existence or not of criminal offence through final judgment in criminal procedure. 
How is manifested the influence of this cause in the appearance of divorces in Kosovo during the period of time 2010-2014, observed this in the context of studied judgments it may be seen from the data presented in the following diagram.

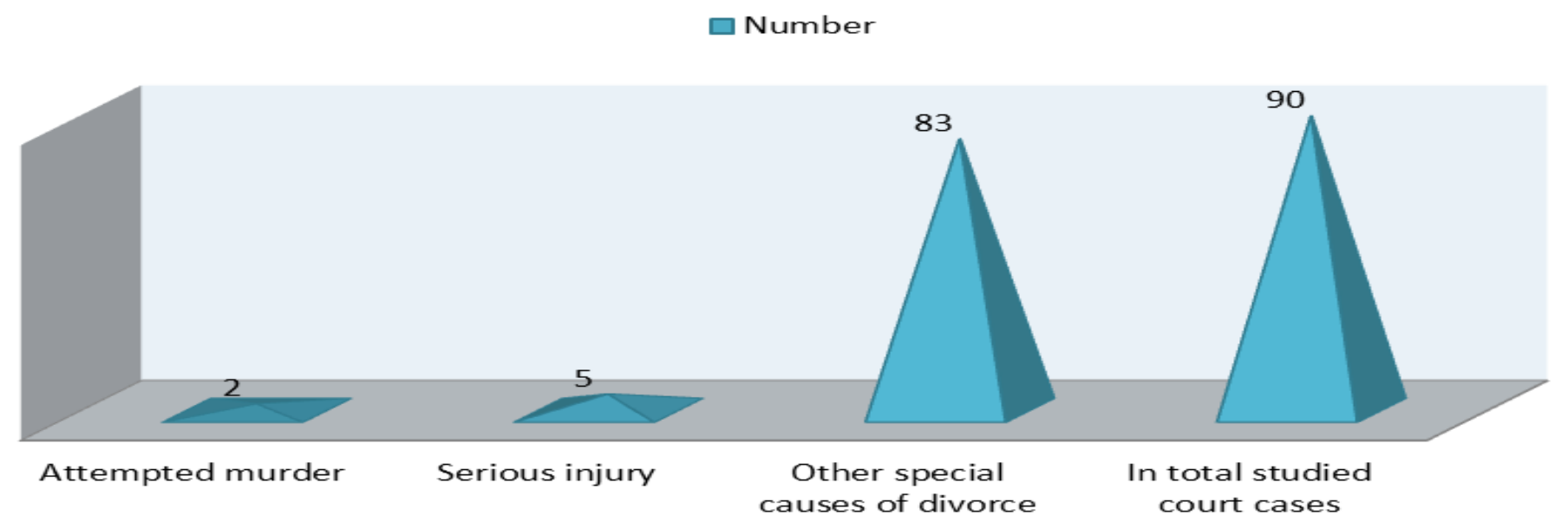

Diagram No-4. The number of divorces because of assassination against the life of the spouse

According to these data from 90 studied court cases in 7 cases the cause of divorce was the assassination against the life of the spouse. As it turns out, this cause participates in the general number of divorce studied court cases to $7.77 \%$. From studied court cases results that in two cases had come to the divorce due to the commission of criminal offence attempted murder against the other spouse, whereas in other five cases due to the commission of criminal offence serious injury against other spouse. From the studied court cases results that in six cases were men who committed criminal offences against their wives, whereas only in one case was the opposite. The cause of husband higher participation within this divorce cause must be linked with the dominant position they continue to have in family and society and existing concepts of female obedience to the family demands.

\subsubsection{Serious Maltreatments}

Maltreatment means unfair treatment, respectively depreciatory, insulting treatment, rude, arrogant behavior as well as behaviors accompanied by physical violence (slapping, pulling hair, isolation etc.) all these exercised against the spouse. In order to use maltreatment as a cause for divorce the legislator requests to be serious, respectively unbearable by the spouse who leads in disruption of marital relations.

How is manifested the influence of this cause in the appearance of divorces in Kosovo during the period of time 2010-2014, observed this in the context of studied judgments it may be seen from the data presented in the following diagram.
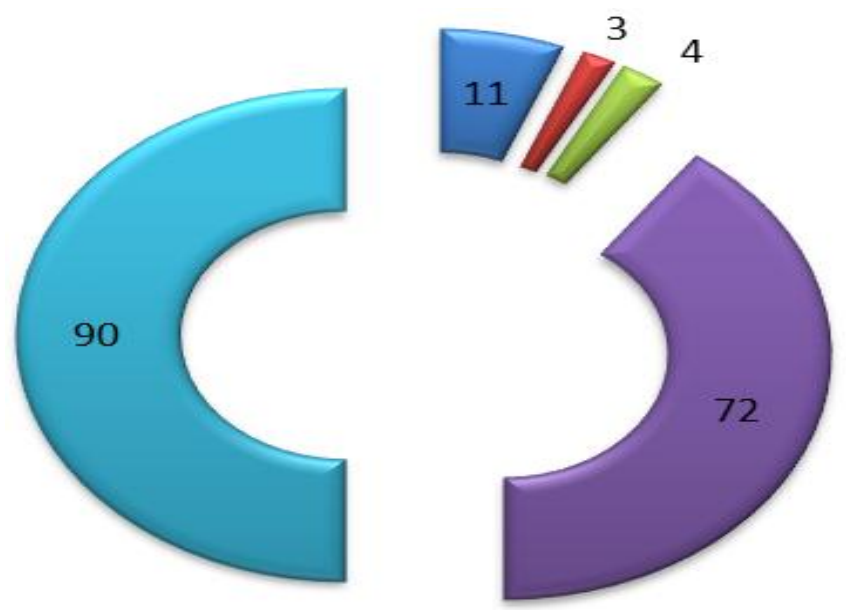

\section{Beating \\ Isolation}

$\square$ Other maltreatment manners

D Other special causes of maltreatment

$\square$ In total studied court cases

Diagram No-5. The number of divorces due to the serious maltreatment

According to these data from 90 studied court cases in 18 cases the cause of divorce was the serious maltreatment of the spouse. As it turns out, this cause participates in the general number of divorce studied court cases to $20 \%$. From studied court cases results that in 11 cases had come to the divorce due to the constant beating of the spouse, whereas in 3 cases due to its isolation within house, whereas in other 4 cases due to other serious maltreatment manners (serious contempt, insult etc.). From the studied court cases results that in 15 cases were men who maltreated their wives, whereas only in 3 cases was the opposite. The cause of husband higher participation within this divorce cause just like abovementioned must be linked with the dominant position they continue to have in family and society and existing concepts of female obedience to the family demands.

\subsubsection{Ill-Intended and Unjustifiable Abandonment}

Care and mutual assistance between spouses is one of the marital obligations during the existence of marriage. Therefore, the violation of this obligation corresponding with ill-intended and unjustifiable abandonment, gives cause to the other spouse to request divorce. Ill-intended and unjustifiable abandonment means facts and circumstances when one spouse abandons another spouse without necessary help and care, whether material or 
moral and does this without any reason. It includes cases when to the spouse is not offered assistance in food, clothing, care in case of illness etc (Gashi et al., 2012).

How is manifested the influence of this cause in the appearance of divorces in Kosovo during the period of time 2010-2014, observed this in the context of studied judgments it may be seen from the data presented in the following diagram.

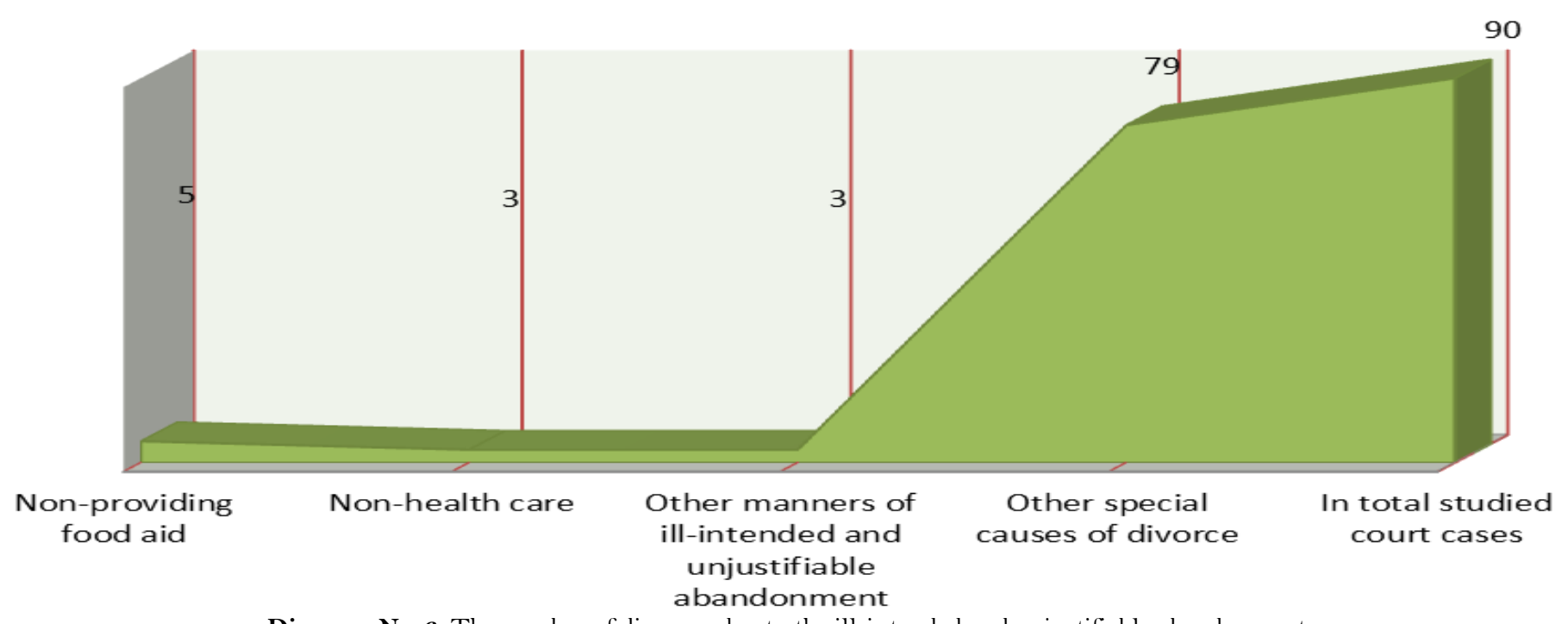

Diagram No-6. The number of divorces due to the ill-intended and unjustifiable abandonment

According to these data from 90 studied court cases in 11 cases the cause of divorce was ill-intended and unjustifiable abandonment. As it turns out, this cause participates in the general number of divorce studied court cases to $11.22 \%$. From studied court cases results that in 5 cases had come to the divorce due to the non-providing food aid to the spouse, whereas in 3 cases due to non-health care to the spouse, whereas in other 3 cases due to other manners of ill-intended and unjustifiable abandonment of the spouse (non-providing help in clothing etc.). From the studied court cases results that in 7 cases were men who conducted ill-intended and unjustifiable abandonment, whereas only in 4 cases was the opposite. According to the results of this research in 7 cases unjustifiable abandonment resulted with the escape of the spouse abroad by leaving him without basic care. A relatively high presence of this cause in the appearance of divorces in Kosovo must be linked with the difficult economic situation prevailing in country and with non-perspective of population towards developments trends extremely slow of economic recovery.

\subsubsection{Incurable Mental Illness and Continuous Incapacity to Act}

Family Law of Kosovo obliges the spouse to take care of other spouse, meaning also taking care in case of any diseases. Nevertheless this Law foresees also the right to divorce in the case of spouse's illness or the occurrence of incapacity to act. It is estimated that the right to divorce due to this cause is related to the existence of severe mental illness, such making the spouses life unbearable. Consequently, any mental illness should not be considered as a cause of divorce (Gashi et al., 2012). Whereas when it comes to incapacity to act, it must be emphasized that this circumstance as a divorce cause may arise when it is proven with relevant decision by court. ${ }^{5}$

How is manifested the influence of this cause in the appearance of divorces in Kosovo during the period of time 2010-2014, observed this in the context of studied judgments it may be seen from the data presented in the following diagram.

82

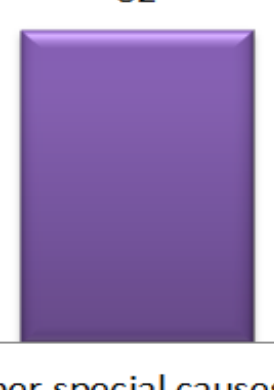

90

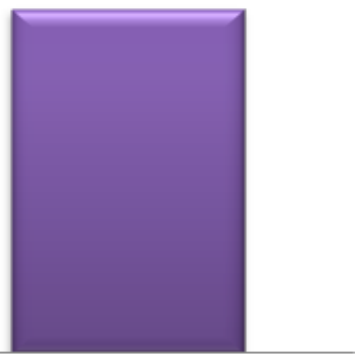

Incurable mental illness Constant incapacity to act Other special causes of In total studied court cases divorce

Diagram No-7. The number of divorces due to the incurable mental illness and constant incapacity to act

According to these data from 90 studied court cases in 8 cases the cause of divorce was incurable mental illness and constant incapacity to act. As it turns out, these two causes participate in the general number of divorce studied court cases to $8.88 \%$. From studied court cases results that in 6 cases had come to the divorce due to the incurable mental illness, whereas in 2 other cases due to the constant incapacity to act. From studied court cases results that all the cases for which had come to the divorce due to the incurable mental illness and constant incapacity to act were of severe nature, such making the spouses life unbearable. Observing this in a gender context among court cases studied in 5 cases these two causes were related with the persons of feminine gender, and only in 3 cases with those of masculine gender. From studied court cases is not seen whether the claimant spouse has been

${ }^{5}$ It is worth mentioning the fact that mental illness may be one of the causes that can lead in taking the ability to act. 
consistent in fulfillment of marital obligations concerning undertaken actions to heal or facilitate such spiritual situations of the spouse facing such situations.

\subsubsection{Other Causes of Divorce}

As facts, respectively other divorce circumstances observing in the context of article 69 of Family Law of Kosovo are considered also unreasonable interruption of factual cohabitation for more than one year and divorce by mutual agreement. Unreasonable interruption of factual cohabitation exists when one of the spouses for more than one year actually does not live with other spouse. Such is the case when one of the spouses goes abroad and for more than one year does not communicate with the other spouse, and the other spouse does not even know its location either reasons of its departure. Whereas mutual agreements of spouses as a cause of divorce exists when they request divorce by mutual agreement, respectively when they make joint proposal for divorce (Gashi et al., 2012).

How is manifested the influence of this cause in the appearance of divorces in Kosovo during the period of time 2010-2014, observed this in the context of studied judgments it may be seen from the data presented in the following diagram.

In total studied court cases

Other special causes of divorce

Divorce by mutual agreement

Unreasonable interruption of factual cohabitation for more than one year

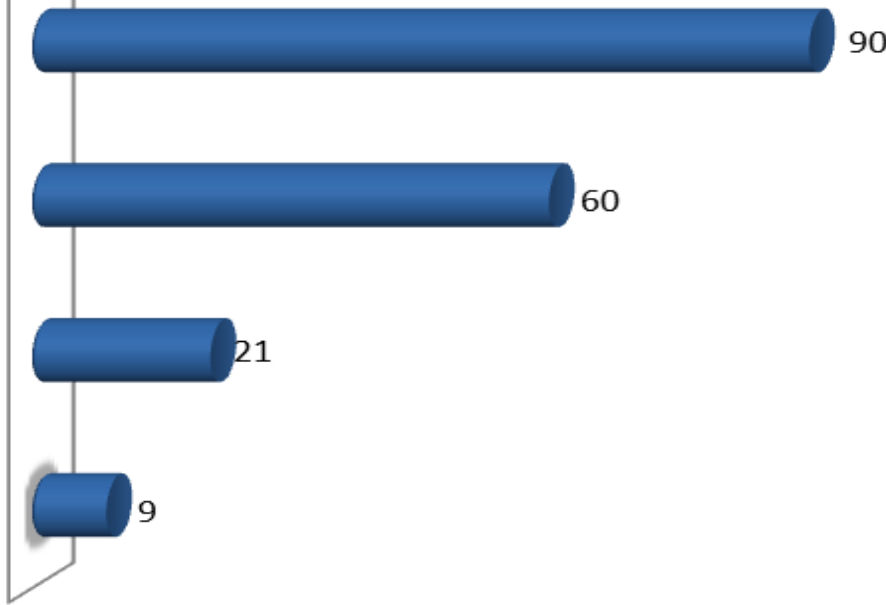

90

Diagram No-8. The number of divorces due to the unreasonable interruption of factual cohabitation for more than one year and divorce by mutual agreement:

According to these data from 90 studied court cases in 30 cases the cause of divorce was unreasonable interruption of factual cohabitation for more than one year and divorce by mutual agreement. As it turns out, these two causes participate in the general number of divorce studied court cases to $33.33 \%$. From studied court cases results that in 21 cases had come to the divorce due to the divorce by mutual agreement, whereas in 9 other cases due to the unreasonable interruption of factual cohabitation for more than one year. From studied court cases results that when they reached an agreement for divorce basically did not tell the reasons that dictated divorce. In meantime concerning unreasonable interruption of factual cohabitation for more than one year claimant spouses in 6 cases had emphasized the fact that the other spouse had lost traces and did not communicate for more than one year, whereas in 3 other cases they communicate but let them know about the fact that their marriage had come to an end.

\section{Divorce Causes}

By dissolution of marriage are presented a numerous legal consequences, social and property nature. These consequences hit spouses and their children. Social circumstances have to deal with the separation of joint property, gifts return, the obligation of food, housing, inheritance, maintenance and raising children etc. In meanwhile, psychological consequences are manifested in the appearance of desperation feeling, aggression, anger and fear etc., (Podvorica, 2011).

Social consequences of divorce manifested in the life of former spouses and their children inevitably are dictated by severe economic and social situation in country. These consequences in Kosovo society mainly hit the feminine gender which continues to be preoccupied with the low level of education and its high unemployment degree. These consequences extend their effects especially in the family of divorced women origin, based on the fact that in more than $85 \%$ of divorce cases, the divorced woman goes in her genus family by becoming a burden of that family.

The social consequences of divorce are manifested also in social aspect. Criminological researches prove that many divorced women and their children continue to become a burden of society. They due to the severe economic situation (by not being employed) are obliged to request for a social support. Bearing in mind the fact Kosovo has an annual budget of only 1 billion and 500 million EURO is clear that the increase of social assistance cases is estimated to be a severe burden for the state.

Psychological consequences of divorce also hit divorced spouses and their children. Psychological consequences that mostly hit spouses are manifested through the appearance of strong anger feelings, anxiety, depression, loneliness, unease and lack of courage for life and activity. This situation creates a different family environment such that affects also children's psychology. Observing in this aspect, children are those who most suffer parent's separation. They feel sadness, fear, anger and are not friendly. Often they feel guilty and helpless for their parent's separation. To those children appear real problems at school, reflected in behavior, communication, collaboration with peers etc.

Divorce also causes other circumstances. In most of the cases divorce causes the reduction of female reproductive ability, giving up from re-marriage, giving up from births in re-marriage, stress, sadness, inadequate children care, low success in teaching of divorced parents children and finally spreading of negative phenomenon as: prostitution, drug, alcoholism and other phenomenon. 


\section{Conclusion}

From modest results of this scientific paper we have come to these conclusions:

1. By divorce should be implied the dissolution of a valid marriage based on the causes specified by law and according to legal proceedings finalized by the issuance of the judgment by court. This definition makes clear the fact that by divorce only a valid marriage has come to dissolution. This means that invalid marriage does not come to dissolution but it is annulled.

2. In Kosovo the divorce issue in these last fifteen years is quite current. The relevance of this issue is determined by the fact that divorces during the post-war period (1999) are more frequent comparison to the past. According to statistical data of the Statistics Agency of Kosovo during the period of time 20102014 were recorded 6388 divorces.

3. The causes of divorce appearance are linked with the democratization process of relations that included Kosovo society in general, the advancement of educational, cultural and economic women's position, family transition (from patriarchal family to modern one), but also the existence of many problems accumulated from the past determined by customary rules handed down from generation to generation.

4. The causes of divorces are of different nature (serious and constant disorders of marital relations) and special. As a special causes are considered to be: unbearable life of spouses, adultery, assassination against the life of the spouse, serious maltreatment, ill-intended and unjustifiable abandonment, incurable mental illness and continuous incapacity to act, unreasonable interruption of factual cohabitation for more than one year and divorce by mutual agreement.

5. By dissolution of marriage are presented a numerous legal consequences, social nature as well as property nature. These consequences hit spouses and their children. Social consequences have to deal with the separation of joint property, gifts return, the obligation of food, housing, inheritance, maintenance and raising children etc. The dissolution of marriage causes also numerous psychological consequences. These consequences which hit divorced spouses and their children are manifested in the appearance of desperation feeling, aggression, anger and fear etc.

\section{References}

District Court, 2008. Former judgment of District Court in Prishtina C.No.67/2088 date 18.06.2008.

Elezi, I., 1983. Albanian criminal customary law. Tirana: University of Tirana. pp: $37-39$.

Gashi, H., A. Aliu and A. Vokshi, 2012. Family law of Kosovo. Prishtina: Commentary. pp: 191-197.

General Statistics During the Years 2010-2014, 2014. Kosovo statistical agency. Retrieved from ask.rks-gov.net/publications/kat_view/36general publications.

Helvacı, S. and F. Erlüle, 2014. Civil law. İstanbul: Marmara University. pp: 174.

Janić, M., R. Korać and Z. Panjović, 1990. Family law, commentary. Beograd: University of Beograde. pp: 144-153.

Law on Family, 2013. Law on family 2013, (Law No.2004/32) entered into force on 20 January 2006.

Luarasi, A., 2001. Family relations. Tirana: University of Tirana. pp: 114-133.

Podvorica, H., 2011. Family law. Prishtina: University of Prishtina. pp: 60-118.

Sahatqija, B., 1987. Family laws in people's Socialist Republic of Albania, Tirana: 270.

Traljić, N. and S. Babić, 2004. Family law. Sarajevo: University of Sarajevo. pp: 211.

\section{Bibliography}

Dural, M., 2014. Item Tufan and silver Mustafa Alper, Turkish Private law, family law. Istanbul: University of Istanbul, $3: 74$.

Turkish Civil Code (8049 - Code number 4721), entered into force on 8 December 2001. 